\title{
Analysis of Mapping Techniques for Mountain Precipitation: A Case Study of Alpine Region, Austria
}

\author{
Abdul Nasir Laghari \\ Department of Energy and Environment \\ Engineering, Quaid-e-Awam University \\ of Engineering, Science and Technology, \\ Nawabshah, Pakistan \\ a.n.laghari@quest.edu.pk
}

\author{
Gordhan Das Walasai \\ Department of Mechanical Engineering, \\ Quaid-e-Awam University of \\ Engineering, Science and Technology, \\ Nawabshah, Pakistan \\ valasai@quest.edu.pk
}

\author{
Daddan Khan Bangwar \\ Department of Civil Engineering, Quaid- \\ e-Awam University of Engineering, \\ Science and Technology, \\ Nawabshah, Pakistan \\ skb_khan2000@yahoo.com
}

\author{
Aftab Hameed Memon \\ Department of Civil Engineering, \\ Quaid-e-Awam University of Engineering, Science and \\ Technology, Nawabshah, Pakistan \\ aftabm78@hotmail.com
}

\author{
Abdul Hannan Shaikh \\ Department of Mathematics, \\ Quaid e Awam University of Engineering, Science, and \\ Technology, Nawabshah, Pakistan \\ hanangul12@yahoo.co.uk
}

\begin{abstract}
Truly representative precipitation map generation of mountain regions is a difficult task. Due to poor gauge representativity, complex topography and uneven density factors make the generation of representative precipitation maps a very difficult task. To generate representative precipitation maps, this study focused on analyzing four different mapping techniques: ordinary kriging, spline technique (SP), inverse distance weighting (IDW) and regression kriging (RK). The generated maps are assessed through cross-validation statistics, spatial cross-consistency test and by water balance approach. The largest prediction error is produced by techniques missing information on co-variables. The ME and RMSE values show that IDW and SP are the most biased techniques. The RK technique produced the best model results with $1.38 \mathrm{~mm}$ and $72.36 \mathrm{~mm}$ ME and RMSE values respectively. The comparative analysis proves that RK model can produce reasonably accurate values at poorly gauged areas, where geographical information compensated the poor availability of local data.
\end{abstract}

Keywords-mountain regions; poor gauge representativity; spatial interpolation techniques

\section{INTRODUCTION}

Scientists generally agree that the earth is undergoing critical climate changes [1-5]. Climatic changes based on the hydrology, development and management of water resources have been under major attention over the years. The distributed hydrological models are gaining huge standing in analyzing and investigating the overall impacts on mountain regions and their environment [6-8]. Distributed hydrological models require input variables like estimates of climatic variables at regular and continuous intervals as pre-requisites for their proper functioning $[5,6,9,10]$. The amount of rainfall is the most vital parameter for any distributed hydrological model. Nevertheless, the amount of rainfall is a matter of various uncertainties like measurement errors, systematic errors during applying interpolation and stochastic errors resulting from the random nature of rainfall. The performance of the models depends heavily upon the accurate estimation of precipitation over specific area and time. The results can be highly compromised [11]. This challenge of reliable and accurate rainfall estimates increases in mountain regions where the geography is complex and measuring stations are scattered over vast areas and concentrated in the valleys [12-14]. The measurement of accurate data for the mountainous range is a very difficult task, resulting in poor representation in the model that analyzes the various rainfall patterns. Resultantly, in these types of situations, when no single method is optimal nor the accuracy of a specific interpolation technique is proven, the performance relies on the variable under study, spatial configuration, and the assumptions used in the estimation [1517]. The accuracy of measured data under a certain technique can be verified by comparing and analyzing by applying different techniques to the same data. In order to achieve this objective, the current study analyzes the range of stochastic and deterministic mapping techniques to estimate the values at ungauged locations.

\section{DATA AND MODELS}

\section{A. Study Area}

The study was carried out at the Alpine area of Kitzbühl Ache region situated in the Austrian Eastern Province of Tyrol with an area of about $2000 \mathrm{~km}^{2}$. Complete details about the study region are given in [18]. The available 30 year time series (1960-1990) of mean annual precipitation of 14 gauge stations are taken into consideration for spatial interpolation. The catchment topography is highly rugged with elevation that ranges from $400 \mathrm{~m}$ to $2400 \mathrm{~m}$ above m.s.l as shown in Figure 1 . The catchment shows strong seasonal precipitation behaviors. 


\section{B. Spatial Interpolation Techniques}

Mapping techniques are categorized into deterministic and stochastic approaches. The former technique includes inverse distance weighing and spline and is used for interpolation of precipitation, whereas, the later technique includes ordinary kriging [19-21]. The regression is carried out on the basis of spatial correlation of the different variables [22-25]. The model is able to remove the drifts with validated intrinsic hypothesis $[17,26]$. This approach has been used for climatic mapping [20, 26-28]. These techniques are briefly presented here, whereas the detailed discussion is referred to $[20,29,30]$.

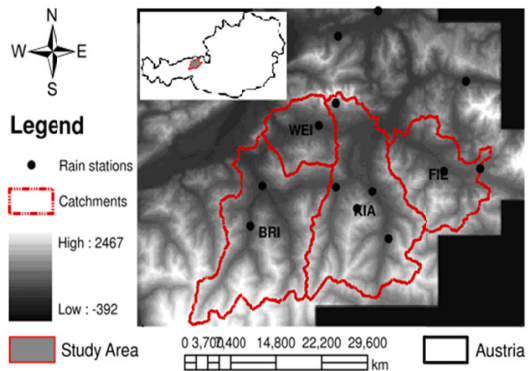

Fig. 1. Study area with locations of 14 rain gauge stations

\section{IDW Technique}

It is form of a deterministic technique that interpolates climatic data by averaging sample values in the neighborhood of each unknown point [31-33]. It's assumed that the variables estimated have decreasing influence or weight with increasing distance from known locations. The formula is given as:

$$
\begin{aligned}
& \hat{T}(X)=\sum_{i} \lambda_{i} * T\left(X_{i}\right) \\
& \lambda_{i}=\frac{1}{d(x, x)^{p} \cdot S} \\
& S=\sum_{i} \frac{1}{d\left(x, x_{i}\right)^{p}}, \text { follows } \sum_{i} \lambda_{i}=1 .
\end{aligned}
$$

where $\hat{T}(X)=$ interpolated value at location $x, \lambda_{i}=$ the weight of observed values at the $\mathrm{i}^{\text {th }}$ location, $T\left(X_{i}\right)=$ observed values at $\mathrm{i}^{\text {th }}$ location, $d\left(x, x_{i}\right)=$ distance from known point to interpreted point, and $P=$ weighting power. The choice of power can significantly influence the interpolation results. High power assigns more weightage to closer points and results in more information, while lower power assigns more weightage to faraway samples with little information.

\section{SP Technique}

It is a deterministic technique, which represents 2dimensional curves on 3-dimensional surfaces [34]. The technique assigns the mathematical functions to certain number of neighboring points that decrease the whole surface curvature. This produces an even surface while passing around the sample points. This is alike to fit a rubber piece across the calculated sample points whilst decreasing the entire surface curvature. The techniques commonly used are regularized, and tension. The first one generates the uniform changing surface with values that may remain outside the sample data range, while the other one influences the rigidity of the surface with values confined by the sample data range. After visual inspection and results through cross-validation statistics, the regularized spline method was selected from both types. The following formula is used for surface interpolation:

$$
\begin{aligned}
& \hat{T}(X)=f\left(x_{i}, y_{i}\right)+\sum_{i=1}^{N} \lambda_{i} R\left(r_{i}\right) \\
& R(r)=\frac{1}{2 \pi}\left\{\frac{r^{2}}{4}\left[\ln \left(\frac{r}{2 \tau}\right)+c-1\right]\right. \\
& \left.+\tau^{2}\left[K_{0}\left(\frac{r}{\tau}\right)+c+\ln \left(\frac{r}{2 \pi}\right)\right]\right\} \\
& f\left(x_{i}, y_{i}\right)=a_{1}+a_{2} x+a_{3} y
\end{aligned}
$$

where $\hat{T}(X)=$ interpolated spline value at location $x, f\left(x_{i}, y_{i}\right)=$ unknown smooth function, $\lambda_{i}=$ the coefficients found by a solution of a system of linear equations, $r_{i}=$ the distance from known point to interpreted point, $K_{0}=$ the modified Bessel function, $C=$ the constant equal to 0.577215 , and $\alpha_{i}=$ the coefficients found by a solution of a system of linear equations.

\section{E. OK Technique}

This technique uses a semivariogram for spatial prediction and works the same way as IDW works, which weights the neighboring measured values. However, weights are not only based on distances but also depend on total spatial arrangement of known points. Author in [35] developed a general formula for kriging, after a first use of the theory in the mining industry by D.L. Krige:

$$
\hat{T}\left(X_{0}\right)=\sum_{i=1}^{n} \lambda_{i} \cdot T\left(X_{i}\right)
$$

where $\hat{T}\left(X_{0}\right)=$ the interpolated value at location $x, T\left(X_{i}\right)=$ the observed value at $\mathrm{i}^{\text {th }}$ location, and $\lambda_{i}=$ the weight of observed values at the $i^{\text {th }}$ location. The $\lambda_{i}$ depends on: Fitting model to the number of measured points, distance to the prediction location and spatial relationships among the measured values around the prediction locations. Kriging minimizes the estimator variance and ensures the unbiased estimation often known as "best linear unbiased estimator (BLUE)" with weights sum to unity [36]. Estimator variance can be achieved by:

$$
\sum_{i=1}^{n} \lambda_{i} \gamma\left(X_{i}, X_{j}\right)+\varphi=\gamma\left(X_{j}, X_{0}\right)
$$

for all $j$, where $\varphi=$ Lagrangian multiplicator. After performing semivariogram analysis, the Gaussian variogram model is selected as a best-fit model from all other models to predict $\hat{T}\left(X_{0}\right)$, and the weights $\lambda_{i}$ are calculated from the matrix equation:

$$
c=A^{-1} . b, \quad c=\left[\begin{array}{c}
\lambda_{i} \\
\phi
\end{array}\right]
$$


where matrix $A$ contains the semivariances of all data point pairs, $b$ is a vector containing semivariances between the location of interest and observed point. $\lambda_{i}$ is the weight to be calculated [20, 37-41].

\section{F. RK Technique}

Authors in [17] conclude that ordinary kriging does not produce representative precipitation values in mountain regions all the time. Alternative techniques might fully utilize the relationship between predicted variable and co-variables for variability analysis. Two of these techniques are cokriging and regression kriging. Due to poor cross-covariance between precipitation and any topographical variable, the former application did not produce good results. However, in such situations regression kriging seemed the natural choice, which is commonly used in hydro-sciences [42, 43]. The technique defines the relationship between target and co-variables in order to predict the values at grid nodes through linear regression. The auxiliary variables are easy to measure, they provide an alternative to target variable at the under sampled locations to model and quantify the existing patterns. To quantify the existing trend of the variable and its variability in a regression model, we preferred to use multiple linear regressions - the further extension of straightforward linear regression with the variety of descriptive variables. As altitude alone flopped to signify the variation of precipitation sufficiently, we tested other variables like slope, topographic index, aspect, hill shade, curvature etc. These extra explanatory variables were obtained from the elevation model, in order to make better predictions of the target variables at grid nodes of the DEM. We adopted stepwise procedures to select the most crucial variables and the subsequent regression equation to predict the target variable at un-sampled locations. The regression led to a three parameter equation, significant at $5 \%$ level, explaining $62 \%$ of variability of precipitation.

$$
\begin{aligned}
\hat{T}_{R}:= & 1075.94+42.59 *[\text { Hill }- \text { shade }] \\
& +0.26 *[D E M]-13.98 *[\text { Slope }]
\end{aligned}
$$

The resulting regression residuals $(\varepsilon)$ are further kriged at grid nodes by fitting variogram models, and then finally both values are summed up to predict the target variable values.

$$
\hat{T}_{R K}(X)=\hat{T}_{R}(X)+\hat{\varepsilon}_{O K}(X)
$$

where $\hat{T}_{R K}=$ Combined predicted values of target variable, $\hat{T}_{R}=$ Regression predicted values of target variable, $\hat{\varepsilon}_{O K}=$ Kriged values of regression residuals.

\section{VALIDATION METHODS}

The mapping techniques performance was assessed by following three steps:

\section{A. Cross-Validation Statistics}

The cross validation method depends on eliminating one sample location (measurement station) from the data set at a time and calculating the value of the removed sample with the remaining data points. This routine was followed for each measurement station. The comparative indices were then used as a measure of prediction quality by the ME and the RMSE, which are defined as follows:

$$
\begin{aligned}
& M E=\frac{1}{n} \sum_{i=1}^{n}\left(\hat{T}_{i}-T_{i}\right) \\
& R M S E=\left\{\frac{1}{n} \sum_{i=1}^{n}\left(\hat{T}_{i}-T_{i}\right)^{2}\right\}^{0.5}
\end{aligned}
$$

where $n$ is the number of validation points, and $\hat{T}_{i} \& T_{i}$ are the predicted and observed values at location $i$. The ME criterion is used to check the conditional bias property, while the RMSE criterion assesses the precision quality. A smaller value of RMSE indicates higher accuracy and vice versa. Cross validation statistics can be used to find the optimal mapping technique, however, the presence of short range correlations in data may raise questions regarding the reliability of its statistical results [35].

\section{B. Cross-Consistency}

A second step to analyze reliability and consistency of predictions, spatial cross-consistency approach was adopted [44]. All statistical parameters of different calculated precipitation mapping estimates were compared with a referenced precipitation map (RPM). This RPM was carefully produced during a 4 year project (www.waterpool.org) in which different experts from different institutes were involved, and results were consistent with water balance estimates.

\section{Water Balance Approach}

Finally all calculated precipitation maps including the RPM were evaluated by means of a general water balance approach.

$$
\begin{aligned}
& Q(\text { discharge })=P(\text { precipitation }) \\
& -E T(\text { evapotranspiration })-\Delta S(\text { Storage changes })
\end{aligned}
$$

Gridded discharges were calculated for each mapping technique as a result of subtraction of actual evapotranspiration grid estimates from interpolated mapping precipitation grid estimates. The actual evapotranspiration values are obtained from the hydrological Atlas of Austria. Storage changes can be ignored, as for long-range mean annual water balances; it was assumed that there is no sensible change in the water contents of different reservoirs, e.g. groundwater, snow cover [44, 45]. The difference between the calculated discharges with observed discharges gives a measure for the reliability and consistency of the precipitation.

\section{RESULTS AND DISCUSSION}

The ME values clearly indicate the superiority of RK technique over the other techniques, showing almost $42 \%$ less bias than OK. Whereas IDW and SP techniques produce higher bias, almost 2 to 5 times higher than OK technique. The RMSE results also reveal the primacy of RK technique over the other ones. However, all techniques yield high uncertainty in calculated values. Thus, considering co-variables into account certainly improves the performance by decreasing RMSE values from 111 to 72 . The spatial cross-consistency tests are also conducted by computing precipitation maps with 
referenced precipitation raster. The same strategy was earlier adopted in [46]. The comparison results are given in Figure 2.

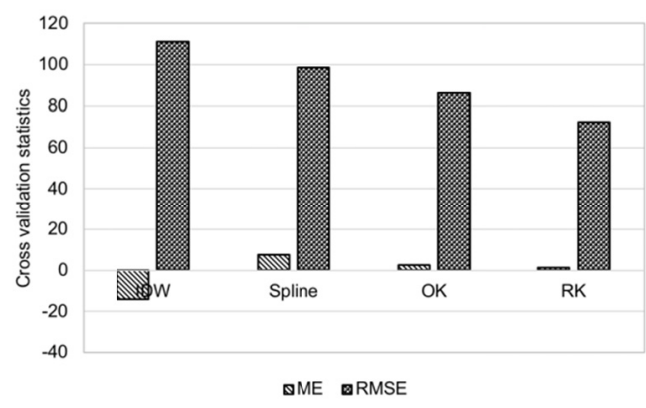

Fig. 2. Cross validation statistics of four mapping techniques applied in study region are the $\mathrm{ME}$ and RMSE

The statistical parameters clearly show the visible differences. However, the RK technique yields the most promising results except in maximum values due to the incorporation of topographical information. Similarly the percentile variation in RK map is closely matched with referenced map. To further analyze all techniques we analyzed their performances, first at 4 catchment levels and then through elevation zones of the whole basin (Figures 3 and 4). The position of gauge stations are highly biased, more than $80 \%$ stations are located below $1000 \mathrm{~m}$ (Zone-1), covering only $32 \%$ of basin area. Zones 2 and 3 contain only one station each, with covering $39 \%$ and $26 \%$ of area respectively. The top most zone- 4 possesses only $3 \%$ area without any gauge station.

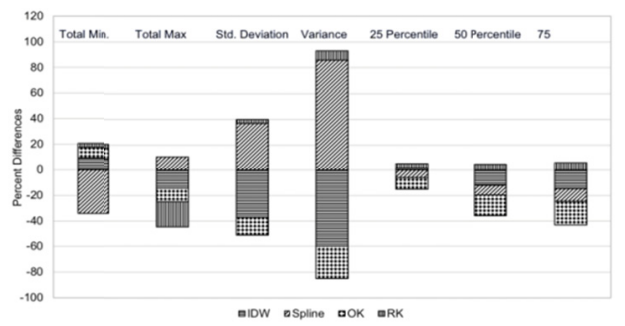

Fig. 3. Summary statistics of percent differences between RPM and computed precipitation estimates by IDW, Spline, OK and RK for the entire region. Negative values indicate a lower value with respect to the referenced map value, while positive values indicate the opposite.

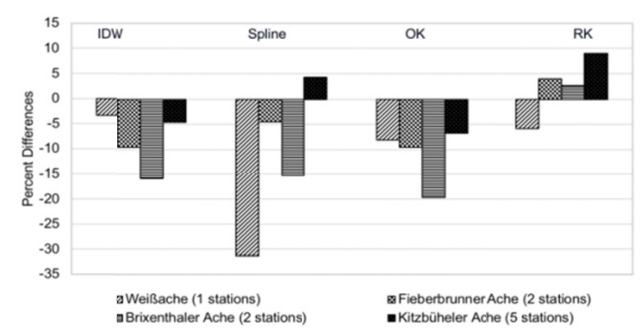

Fig. 4. Comparative statistics of percent differences between RPM and computed precipitation estimates by IDW, Spline, OK and RK at four basins. Negative values indicate the less value from the referenced map and positive values indicate the opposite.

The basin level values follow the same pattern of mean annual values in the region. RK method is found to present better result in three basins, whereas in Kitzbüleher Ache the other techniques have better estimates. The superiority of usual techniques like IDW, spline over geostatistical techniques justifies the conclusions of many other studies. These conclusions are strengthened by further analysis on the basis of altitude. Without elevation information the IDW, spline and OK techniques performed comparatively well below $1000 \mathrm{~m}$ altitude which contains $86 \%$ of the total stations under study. However, at the higher altitudes these three techniques could not be effective, where the consistency ranges at $8 \%$ at zone- 2 and $33 \%$ at zone- 4 resulting in relegation of their ability at higher sparse data zones. During semivariogram modeling the performance of OK at high zone was poor, as the spatial dependence resulted to be higher at zone 1 and weakened in zones 2 and 3 . For analyzing the mapping techniques comparatively, all stations were included in the final mapping. The better results from RK at higher zones prove the importance of geographical information in estimating the mapping at higher sparse data zones. A water balance approach was adopted for the four interpolation precipitation maps in order to validate the RPM. Mean annual evapotranspiration estimates of the whole region were taken from the hydrological atlas of Austria. Total runoff was computed from precipitation maps and evapotranspiration estimates. The difference between gauged runoff and computed runoff found out to be only $0.4 \%$ with RPM, 2.7\% with RK and 13-20\% with other techniques. These outcomes validate the overall superiority of RK technique in the higher altitude region with sparse data.

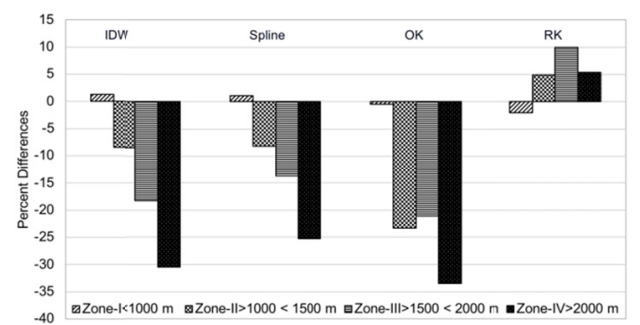

Fig. 5. Comparative statistics of percent differences between RPM and computed precipitation estimates by IDW, Spline, OK and RK at four elevation zones. Negative values indicate the less value from the referenced map and positive values indicate vthe opposite.

\section{CONCLUSION}

Comprehensive analysis clearly indicates that RK model produces reasonably accurate average annual precipitation values. The primacy of this technique is particularly observed at high altitude sparse data zones where mapping variables are unobtainable. However, the spline and IDW model results also produce good results over geostatistical techniques at a low level height with a wide network of gauge stations.

\section{REFERENCES}

[1] B. Klove, P. Ala-Aho, G. Bertrand, J. J. Gurdak, H. Kupfersberger, J. Kværner, T. Muotka, H. Mykra, E. Preda, P. Rossi, C. B. Uvo, E. Velasco, M. Pulido-Velazquez, "Climate change impacts on groundwater and dependent ecosystems", Journal of Hydrology, Vol. 518B, pp. 250-266, 2014

[2] H.-M. Fussel, A. Jol, A. Marx, M. Hilden, A. Aparicio, A. Bastrup-Birk, A. Bigano, S. Castellari, M. Erhard, B. Georgi, Climate change, impacts 
and vulnerability in Europe 2016-An indicator-based report, EU Publications, 2017

[3] M. Burke, J. Dykema, D. B. Lobell, E. Miguel, S. Satyanath, "Incorporating climate uncertainty into estimates of climate change impacts", Review of Economics and Statistics, Vol. 97, No. 2, pp. 461471,2015

[4] C. B. Field, V. R. Barros, K. Mach, M. Mastrandrea, Climate change 2014: impacts, adaptation, and vulnerability. Vol. 1, Cambridge University Press, 2014

[5] A. Laghari, D. Vanham, W. Rauch, "To what extent does climate change result in a shift in Alpine hydrology? A case study in the Austrian Alps", Hydrological Sciences Journal, Vol. 57, No. 1, pp. 103-117, 2012

[6] D. Viviroli, M. Zappa, J. Gurtz, R. Weingartner, "An introduction to the hydrological modelling system PREVAH and its pre-and postprocessing-tools", Environmental Modelling \& Software, Vol. 24, No. 10, pp. 1209-1222, 2009

[7] R. Cibin, P. Athira, K. Sudheer, I. Chaubey, "Application of distributed hydrological models for predictions in ungauged basins: a method to quantify predictive uncertainty", Hydrological Processes, Vol. 28, No. 4, pp. 2033-2045, 2014

[8] Y. Chen, J. Li, H. Xu, "Improving flood forecasting capability of physically based distributed hydrological models by parameter optimization", Hydrology and Earth System Sciences, Vol. 20, No. 1, pp. 375-392, 2016

[9] K. X. Yu, L. Gottschalk, L. Xiong, Z. Li, Li, "Estimation of the annual runoff distribution from moments of climatic variables", Journal of Hydrology, Vol. 531, pp. 1081-1094, 2015

[10] Z. K. Tesemma, Y. Wei, M. C. Peel, A. W. Western, "Including the dynamic relationship between climatic variables and leaf area index in a hydrological model to improve streamflow prediction under a changing climate", Hydrology and Earth System Sciences, Vol. 19, No. 6, pp. 2821-2836, 2015

[11] K. Beven, "How far can we go in distributed hydrological modelling?", Hydrology and Earth System Sciences, Vol. 5, No. 1, pp. 1-12, 2001

[12] E. Lepuschitz, "Geographic information systems in mountain risk and disaster management", Applied Geography, Vol. 63, pp. 212-219, 2015

[13] S. Takaoka, "Origin and geographical characteristics of ponds in a high mountain region of central Japan", Limnology, Vol. 16, No. 2, pp. 103112,2015

[14] N. Boers, B. Bookhagen, N. Marwan, J. Kurths, "Spatiotemporal characteristics and synchronization of extreme rainfall in South America with focus on the Andes Mountain range", Climate Dynamics, Vol. 46, No. 1-2, pp. 601-617, 2016

[15] J. Creutin, C. Obled, "Objective analyses and mapping techniques for rainfall fields: an objective comparison", Water Resources Research, Vol. 18, No. 2, pp. 413-431, 1982

[16] D. D. Weber, E. J. Englund, "Evaluation and comparison of spatial interpolators II", Mathematical Geology, Vol. 26, No. 5, pp. 589-603, 1994

[17] C. Prudhomme, D. W. Reed, "Mapping extreme rainfall in a mountainous region using geostatistical techniques: a case study in Scotland", International Journal of Climatology, Vol. 19, No. 12, pp. 1337-1356, 1999

[18] D. Vanham, E. Fleischhacker, W. Rauch, "Technical Note: Seasonality in alpine water resources management? a regional assessment", Hydrology and Earth System Sciences, Vol. 12, No. 1, pp. 91-100, 2008

[19] M. Knotters, D. Brus, J. O. Voshaar, "A comparison of kriging, cokriging and kriging combined with regression for spatial interpolation of horizon depth with censored observations", Geoderma, Vol. 67, No. 3-4, pp. 227-246, 1995

[20] I. O. A. Odeha, A. B. McBratney, D. Chittleborough, "Further results on prediction of soil properties from terrain attributes: heterotopic cokriging and regression-kriging", Geoderma, Vol. 67, No. 3-4, pp. 215-226, 1995

[21] I. O. A. Odeha, A. B. McBratney, D. J. Chittleborough, "Spatial prediction of soil properties from landform attributes derived from a digital elevation model", Geoderma, Vol. 63, No. 3-4, pp. 197-214, 1994
[22] V. Chaplot, C. Walter, P. Curmi, "Improving soil hydromorphy prediction according to DEM resolution and available pedological data", Geoderma, Vol. 97, No. 3-4, pp. 405-422, 2000

[23] I. D. Moore, P. E. Gessler, G. A. E. Nielsen, G. A. Peterson, "Soil attribute prediction using terrain analysis", Soil Science Society of America Journal, Vol. 57, No. 2, pp. 443-452, 1993

[24] J. L. Richardson, W. J. Edmonds, "Linear regression estimations of Jenny's relative effectiveness of state factors equation", Soil Science, Vol. 144, No. 3, pp. 203-208, 1987

[25] J. A. Thompson, J. C. Bell, C. A. Butler, "Digital elevation model resolution: effects on terrain attribute calculation and quantitative soillandscape modeling", Geoderma, Vol. 100, No. 1-2, pp. 67-89, 2001

[26] M. R. Holdaway, "Spatial modeling and interpolation of monthly temperature using kriging", Climate Research, Vol. 6, pp. 215-225, 1996

[27] A. Martinez-Cob, "Multivariate geostatistical analysis of evapotranspiration and precipitation in mountainous terrain", Journal of Hydrology, Vol. 174, No. 1-2, pp. 19-35, 1996

[28] D. L. Phillips, J. Dolph, D. Marks, "A comparison of geostatistical procedures for spatial analysis of precipitation in mountainous terrain", Agricultural and forest meteorology, Vol. 58, No. 1-2, pp. 119-141, 1992

[29] P. Goovaerts, Geostatistics for natural resources evaluation. Oxford University Press, 1997

[30] T. Hengl, G. B. Heuvelink, A. Stein, Comparison of kriging with external drift and regression kriging, ITC, 2003

[31] P. A. Burrough, R. A. McDonnell, C. D. Lloyd, Principles of geographical information systems, Oxford University Press, 2015

[32] D. R. Legates, C. J. Willmott, "Mean seasonal and spatial variability in global surface air temperature", Theoretical and Applied Climatology, Vol. 41, No. 1-2, pp. 11-21, 1990

[33] C. Stallings, R. Huffman, S. Khorram, Z. Guo, Linking gleams and GIS, Paper-American Society of Agricultural Engineers (USA), 1992

[34] M. Hutchinson, P. Gessler, "Splines-more than just a smooth interpolator", Geoderma, Vol. 62, No. 1-3, pp. 45-67, 1994

[35] G. Matheron, Le krigeage universel: cahiers du Centre de Morphologie Mathematique, École nationale supérieure des mines de Paris, 1969 (in French)

[36] R. Webster, M. A. Oliver, Geostatistics for environmental scientists, John Wiley \& Sons, 2007

[37] J. C. Davis, Statistics and Data Analysis in Geology, John Wiley \& Sons, 1986

[38] C. V. Deutsch, A. G. Journel, GSLIB Geostatistical Software Library and User's Guide, Oxford University Press, 1992

[39] G. W. Heine, "A controlled study of some two-dimensional interpolation methods", COGS Computer Contributions, Vol. 3, No. 2, pp. 60-72, 1986

[40] N. S. N. Lam, "Spatial interpolation methods: a review", The American Cartographer, Vol. 10, No. 2, pp. 129-150, 1983

[41] A. G. Royle, F. L. Clausen, P. Frederiksen, "Practical universal kriging and automatic contouring”, Geoprocessing, Vol. 1, pp. 377-394, 1981

[42] S. Ahmed, G. De Marsily, "Comparison of geostatistical methods for estimating transmissivity using data on transmissivity and specific capacity", Water Resources Research, Vol. 23, No. 9, pp. 1717-1737, 1987

[43] J. Delhomme, "Kriging in the hydrosciences", Advances in Water Resources, Vol. 1, pp. 251-266, 1978

[44] J. Hofierka, J. Parajka, H. Mitasova, L. Mitas, "Multivariate interpolation of precipitation using regularized spline with tension", Transactions in GIS, Vol. 6, No. 2, pp. 135-150, 2002

[45] M. Kuhn, H. Escher-Vetter, "Die Reaktion der österreichischen Gletscher und ihres Abflusses auf Änderungen von Temperatur und Niederschlag", Osterreichische Wasser-und Abfallwirtschaft, Vol. 56, No. 1-2, pp. 10-16, 2004

[46] S. G. Custer, P. Fames, J. P. Wilson, R. D. Snyder, "A Comparison of Hand and Spline-Drawn Precipitation Maps for mantainous Montana", Journal of the American Water Resources Association, Vol. 32, No. 2, pp. 393-405, 1996 